\title{
QUALIDADE TECNOLÓGICA EM DIFERENTES PORÇÕES DO COLMO E PRODUTIVIDADE DA CANA-DE-AÇÚCAR SOB EFEITO DE MATURADORES (')
}

\author{
GLAUBER HENRIQUE PEREIRA LEITE $\left({ }^{2}\right)$; CARLOS ALEXANDRE COSTA CRUSCIOL $\left({ }^{2, *}\right)$; \\ GABRIELA FERRAZ DE SIQUEIRA $\left({ }^{2}\right)$; MARCELO DE ALMEIDA SILVA $\left({ }^{3}\right)$
}

\begin{abstract}
RESUMO
O objetivo deste trabalho foi avaliar a qualidade tecnológica da cana-de-açúcar, variedade RB855453, nas diversas porções do colmo, decorrente da aplicação de maturadores com diferentes mecanismos de ação e a influência na produtividade e na margem de contribuição agrícola. O delineamento experimental foi em blocos casualizados, com seis repetições. Os tratamentos constituíram-se da aplicação de três maturadores, sendo dois da classe dos inibidores do crescimento - glifosato, sulfometuron metil, e um da classe dos retardantes do crescimento - $\mathrm{KNO}_{3}$, com a adição de $1 \%$ de óleo vegetal, e a maturação natural como testemunha. Os tratamentos com $\mathrm{KNO}_{3}$ e sulfometuron metil, assim como a testemunha, não promoveram prejuízos ao desenvolvimento dos colmos. Os tratamentos com glifosato e sulfometuron metil propiciaram melhoria na qualidade tecnológica da matéria-prima, determinada até os 35 dias após aplicação, contribuindo para o processo de maturação e possibilitando antecipar o corte em relação à maturação natural (testemunha) e ao tratamento com $\mathrm{KNO}_{3}$, propiciando maior retorno econômico. O tratamento com glifosato reduziu a produtividade de colmos, mas elevou a pol da cana na porção superior dos colmos, possibilitando maior altura de desponte.
\end{abstract}

Palavras-chave: Saccharum spp., biometria, glifosato, nitrato de potássio, sulfometuron metil, maturação.

\section{ABSTRACT \\ TECHNOLOGICAL QUALITY AT DIFFERENT PORTIONS OF THE STALK AND PRODUCTIVITY OF SUGARCANE UNDER EFFECT OF RIPENERS}

The objective of this research was to evaluate the technological quality of sugarcane, variety RB855453, in different portions of the stalks after the application of ripeners with distinct mechanisms of action and the effects on productivity and agricultural contribution margin. The experimental design was the completely randomized block with six replications. The treatments consisted of the application of three ripeners (two of them within the class of growth inhibitors - glyphosate, sulfometuron methyl) and one within the class of growth retardants $\left(\mathrm{KNO}_{3}\right)$, with the addition $1 \%$ of vegetable oil, and the control (natural ripening). Treatments with $\mathrm{KNO}_{3}$ and sulfometuron methyl, as well as control, did not cause any damage to the development of stalks. Treatments with glyphosate and sulfometuron methyl increased technological quality of the raw material, evaluated up to 35 days after application; this contributed to the ripening process and allowed harvest to occur in advance when compared to the control (natural ripening) and the treatment with $\mathrm{KNO}_{3}$, increasing the profit. Treatment with glyphosate reduced productivity of stalks, but increased pol in cane in the superior portion of the stalks, which increased cutting height.

Key words: Saccharum spp., biometry, glyphosate, potassium nitrate, sulfometuron methyl, ripening.

(1) Recebido para publicação em 27 de agosto de 2008 e aceito em 10 de maio de 2010.

(²) Universidade Estadual Paulista, Faculdade de Ciências Agronômicas, Departamento de Produção Vegetal, Caixa Postal 237, 18610-307 Botucatu (SP). E-mail: ghpleite@yahoo.com.br; gaferraz@fca.unesp.br; crusciol@fca.unesp.br $\left(^{*}\right)$ Autor correspondente.

(3) Agência Paulista de Tecnologia dos Agronegócios, Polo Centro-Oeste, Rodovia SP 304, km 304, Caixa Postal 66, 17201-970 Jaú (SP). E-mail: marcelosilva@apta.sp.gov.br 


\section{INTRODUÇÃO}

O sucesso na produção de áçucar e álcool pela indústria sucroalcooleira está diretamente associado ao fornecimento de matéria-prima de alta qualidade tecnológica. Atualmente, com a expansão da safra e das lavouras canavieiras, o emprego de maturadores tem sido de significativa relevância para o suprimento do complexo industrial, tendo em vista que permite induzir o processo de maturação da cana-de-açúcar mesmo em condições climáticas que favorecem a vegetação e, por conseqüência, dispor às unidades industriais matériaprima de qualidade.

O processo de maturação da cana-de-açúcar na Região Sudeste do Brasil ocorre naturalmente a partir de abril/maio com clímax em agosto/setembro. Neste período, as condições climáticas, determinantes para tal processo, caracterizam-se pela gradativa queda da temperatura e diminuição das precipitações pluviais (Deuber, 1988).

Os maturadores, definidos como reguladores vegetais, agem alterando a morfologia e a fisiologia da planta, podendo levar a modificações qualitativas e quantitativas na produção (CASTRO, 1999). Dentre os agentes químicos utilizados como maturadores destacam-se o etefon, o etil-trinexapac, o glifosato e o sulfometuron metil.

Os produtos do grupo químico das glicinas substituídas têm por particularidade inibir a síntese de aminoácidos de cadeia aromática, fenilalanina, tirosina e triptofano, este último, precursor da síntese de ácido indolil acético (IAA), um hormônio vegetal. Em contrapartida, produtos do grupo químico das sulfoniluréias caracterizam-se como potentes inibidores do crescimento vegetal, interferindo nos processos de crescimento e divisão celular, contudonão comprometem diretamente o sistema mitótico e a síntese de DNA. Aparentemente, não bloqueiam de forma direta a ação de promotores de crescimento (auxinas, giberelinas e citocininas), porém estimulam fortemente a produção de etileno em função do efeito estressante causado pela fitotoxidez (Ovejero et al., 2004).

Atualmente, produtos cuja composição química contém o nitrato de potássio têm sido empregados nas lavouras de cana-de-açúcar com a mesma finalidade, associado à vantagem de serem menos agressivos ao ambiente, podendo substituir o uso de herbicidas, quando houver nas proximidades da cultura da cana-deaçúcar, culturas sensíveis ao modo de ação destes outros produtos químicos. Tais compostos químicos (nitrato de potássio) têm sido caracterizados como indutores do processo de maturação, classificados como retardantes do crescimento, tendo em vista que o efeito estressante decorrente de sua aplicação tem por consequência estimular a síntese endógena de etileno, hormônio vegetal capaz de promover alterações na fisiologia e morfologia da planta, induzindo tal processo (CASTRO et al., 2002; LeITE, 2005).

O corte basal e apical do colmo na colheita da cana-de-açúcar tem influência sobre o aproveitamento da matéria-prima, tendo em vista que o corte apical pode ser realizado em diferentes alturas (STUPIELLO, 2000). Segundo BARRETO (1991), o caldo extraído da região apical do colmo possui baixa pureza, devido ao baixo teor de sacarose e ao alto teor de compostos não açúcares; no entanto, a inclusão do ponteiro não implica em custos extras, uma vez que a recuperação do açúcar e melaço pode ser compensada em outras etapas da fabricação. Para RuAs et al. (1987), o processamento da cana-de-açúcar sem desponte proporcionou diminuição dos custos agrícolas e aumento da receita industrial, todavia BELODI (1988) obteve menor eficiência geral industrial, sem melhoria nos resultados econômicos. De acordo com ZARPELON (1988), não há diferença quanto à qualidade tecnológica do caldo, considerando a cana com ou sem desponte, porém pela presença de nutrientes na ponta da cana espera-se influência positiva no processo de fermentação. Contudo, a ponta e as folhas incorporam ao caldo maior quantidade de cor (pigmentação), a qual é determinante na qualidade do açúcar (COPERSUCAR, 1999).

Dessa forma, é possível que haja influência dos maturadores sobre a composição e qualidade do caldo extraído nas diferentes partes do colmo, principalmente no terço superior, possibilitando alturas diferentes de desponte e, consequentemente, acarretando menor teor de impurezas na matériaprima fornecida à indústria.

Nesse contexto, o objetivo deste trabalho foi avaliar a qualidade tecnológica da cana-de-açúcar, variedade RB855453, nas diferentes porções do colmo, decorrente da aplicação de maturadores com diferentes mecanismos de ação e a influência na produtividade e na margem de contribuição agrícola.

\section{MATERIAL E MÉTODOS}

O experimento foi desenvolvido sob condições de campo em cana-soca de $1 .^{\circ}$ ano, no período de 14-32006 (aplicação dos maturadores) a 19-4-2006 (colheita), na Fazenda Santa Maria, município de Igaraçu do Tietê, Estado de São Paulo (latitude de $22^{\circ} 38^{\prime} 45^{\prime \prime}$, longitude $48^{\circ} 36^{\prime} 29^{\prime \prime} \mathrm{O}$, altitude $620 \mathrm{~m}$ ). Os dados climáticos diários referentes à precipitação pluvial e às temperaturas máximas, médias e mínimas registrados durante o período experimental foram coletados na Estação Meteorológica da Fazenda São Joaquim, os 


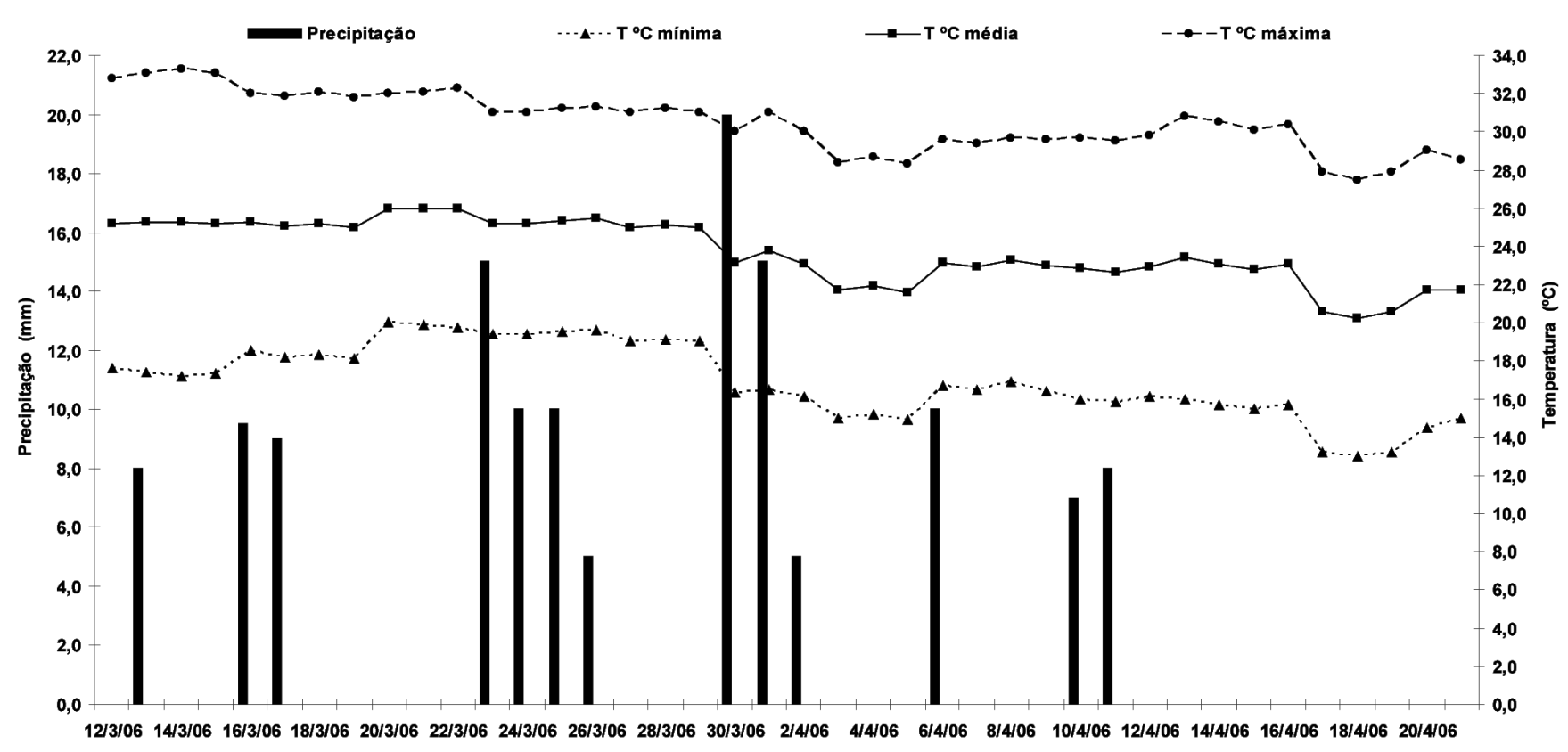

Figura 1. Precipitação pluvial mensal e temperatura do ar (máxima, média e mínima) registradas durante o período experimental na Estação Metereológica da Fazenda São Joaquim, na safra 2006, em Igaraçu do Tietê (SP).

quais caracterizam a região onde foi implantado o experimento (Figura 1).

O delineamento experimental foi em blocos casualizados, com seis repetições. Os tratamentos constituíram-se da aplicação de três maturadores, sendo dois da classe dos inibidores do crescimento (192 $\mathrm{g} \mathrm{ha}^{-1}$ de glifosato; $15 \mathrm{~g} \mathrm{ha}^{-1}$ de sulfometuron metil), e um da classe dos retardantes do crescimento (3 $\mathrm{kg} \mathrm{ha}^{-1}$ de $\mathrm{KNO}_{3}$ ), com a adição de $1 \%$ de óleo vegetal, e a maturação natural como testemunha. Cada parcela foi constituída por oito linhas de $10 \mathrm{~m}$ de comprimento, espaçadas de 1,5 m, contudo para as avaliações foram consideradas as seis linhas centrais, desprezando $1 \mathrm{~m}$ nas extremidades, perfazendo uma área útil de $72 \mathrm{~m}^{2}$.

A aplicação dos maturadores foi realizada em $14 / 3 / 2006$, por meio de equipamento costal pressurizado $\left(\mathrm{CO}_{2}\right)$ com barra de $6 \mathrm{~m}$ de comprimento, em forma de T, com seis bicos de pulverização AXI 11002, e a pressão de trabalho foi de 50 PSI, para a vazão correspondente a $100 \mathrm{~L} \mathrm{ha}^{-1}$. Utilizou-se a variedade RB855453, com média produtividade de colmos, elevado teor de sacarose, precocidade de maturação e média exigência em fertilidade de solo.

As produtividades de colmos (TCH) e açúcar (TAH) na colheita foram determinadas nas quatro fileiras centrais e, duas fileiras de plantas foram destinadas às mensurações tecnológicas, realizadas nas seguintes épocas: $0,14,28$ e 35 dias após aplicação
(DAA). Posteriormente, foi estabelecida a margem de contribuição agrícola (MCA), conforme método descrito em FERNANDES (2003). Na colheita do experimento, foi realizada a contagem de colmos em $10 \mathrm{~m}$ de linha na área útil de cada unidade experimental, obtendo-se posteriormente o respectivo valor por metro.

Em relação à mensuração tecnológica, foi estabelecido um metro linear aleatório a cada época de amostragem, sendo os colmos coletados, submetidos ao desponte na altura da gema apical, à desfolha, seccionados em três porções idênticas (terço inferior, médio e superior), identificados e imediatamente encaminhados para o processamento, segundo o método do Sistema de Pagamento de Cana pelo Teor de Sacarose (SPCTS), conforme descrito em FERNANDES (2003), em que as variáveis consideradas foram pol da cana (PCC), pureza do caldo (PUR), açúcares redutores na cana (ARC) e fibra na cana (F). Para as determinações tecnológicas foram enviadas ao laboratório quatro amostras por parcela, a cada época de amostragem, totalizando 288 amostras, sendo utilizada a média de cada tratamento no estudo estatístico.

Nas plantas destinadas à avaliação tecnológica foi mensurado o comprimento e o diâmetro de colmos, no momento da instalação do experimento (aplicação dos tratamentos) e na colheita, aos 0 e 35 DAA respectivamente. O comprimento dos colmos foi determinado mediante régua graduada em metros, 
da superfície do solo até a região auricular da folha + 1 , ou seja, até a primeira folha com aurícula visível, enquanto o diâmetro foi determinado no terceiro entrenó acima da superfície do solo, com o auxílio de paquímetro digital.

Os resultados foram submetidos à análise de variância, e as médias dos tratamentos foram comparadas pelo teste LSD, a 5\% de probabilidade de erro. Os resultados de épocas de amostragem foram submetidos à análise de regressão, tendo-se adotado, como critério para a escolha do modelo, a magnitude dos coeficientes de regressão significativos, a $5 \%$ de probabilidade pelo teste $t$.

\section{RESULTADOS E DISCUSSÃO}

As condições climáticas no período entre a aplicação dos maturadores (14/3/2006) e a colheita do experimento $(19 / 4 / 2006)$ favoreceram o desenvolvimento vegetativo da cana-de-açúcar, tendo em vista que o período foi caracterizado por elevadas temperaturas médias do ar $\left(25,2^{\circ} \mathrm{C}\right.$ em março e 22,1 ${ }^{\circ} \mathrm{C}$ em abril) e disponibilidade hídrica $(131,50 \mathrm{~mm}$ de chuva acumulados). Entretanto, houve queda gradual da temperatura média do ar, a partir do início de abril até a data da colheita (Figura 1), fator favorável ao estímulo do processo da maturação. A cana-de-açúcar tem crescimento vegetativo ótimo com temperatura oscilando entre 28 e $34{ }^{\circ} \mathrm{C}$, enquanto para a ocorrência da maturação natural, a planta é exigente em temperatura baixa (média mensal igual ou inferior a $21^{\circ} \mathrm{C}$ ), para que haja repouso fisiológico e maior acúmulo de sacarose nos colmos, principalmente em regiões onde não há período de seca definido (CASTRO e KLUGE, 2001).

Foram observadas diferenças significativas no comprimento dos colmos na implantação dos tratamentos (0 DAA), em que valores maiores foram constatados nas parcelas que receberam o tratamento com glifosato, diferindo dos tratamentos com $\mathrm{KNO}_{3}$ e sulfometuron metil, enquanto aos 35 DAA não diferiram entre si (Tabela 1). Portanto, na comparação entre épocas ( 0 e $35 \mathrm{DAA}$ ), os tratamentos com sulfometuron metil, $\mathrm{KNO}_{3}$ e a testemunha (maturação natural) não afetaram a continuidade do processo de desenvolvimento vegetativo da plantas, enquanto o glifosato retardou tal processo (Tabela 1). Provavelmente a condição climática (Figura 1) associada ao mecanismo de ação dos agentes químicos sulfometuron metil e $\mathrm{KNO}_{3}$ não foram suficientes para diminuir o desenvolvimento das plantas, processo fundamental para o acúmulo de sacarose nos colmos, diferentemente do constatado para o composto químico glifosato.
Os resultados, em relação ao glifosato, confirmaram os dados de ROMERo et al. (1996, 1998), que constataram rápida e progressiva redução na taxa de alongamento dos entrenós, principalmente dos imaturos. Segundo Rodrigues e LeITE (2004), na maioria das plantas, o ácido indol acético (AIA) é sintetizado a partir do aminoácido triptofano. O glifosato inibe a atividade da enzima EPSPS (5-enolpiruvilchiquimato3-fosfato sintase), evitando a conversão de chiquimato à corismato, inibindo a biossíntese dos aminoácidos fenilalanina, tirosina e triptofano; estes são precursores de compostos secundários como a lignina, alcalóides, flavonóides e hormônios (OvejERo et al., 2004).

Os tratamentos, independentemente do mecanismo de ação e da manutenção ou retirada da dominânciaapical, nãoinduziramvariaçõessignificativas no diâmetro dos colmos (Tabela 1), permitindo inferir sobre a importância da manisfestação da dominância apical (manutenção da integridade da gema apical) para a continuidade do processo de desenvolvimento vegetativo das plantas, conforme observado através do comprimento dos colmos (Tabela 1).

Os tratamentos afetaram de forma significativa a pol da cana nas diferentes porções do colmo (Figura 2a-c). Na porção inferior do colmo, o tratamento com sulfometuron metil induziu aumento no teor de sacarose com ajuste linear crescente, enquanto o tratamento com glifosato foi ajustado ao modelo quadrático, com máximo acúmulo de sacarose aos 21 DAA ( $\mathrm{PCC}=15,60 \%$ ) (Figura $2 \mathrm{c}$ ). Em relação ao terço médio, os tratamentos elevaram a pol da cana e ajustaram-se ao modelo linear crescente, com exceção da maturação natural (testemunha) (Figura 2b). Por outro lado, na porção superior dos colmos somente o tratamento com glifosato proporcionou aumento do teor de sacarose, com reposta expressa por modelo linear positivo (Figura 2a). Diversos autores têm mostrado melhorias significativas na qualidade dos entrenós apicais da cana-de-açúcar com o emprego de glifosato (Romero et al., 1998; 2000; 2003; CASTRO et al., 2002) e sulfometuron metil (CASTRO et al., 1994; 2003; FERNANDES et al., 2002;) permitindo o desponte mais alto do colmo, contribuindo para o acréscimo na produção de colmos, sem perdas na qualidade.

Com os tratamentos houve influência significativa nos valores de pureza do caldo da cana-de-açúcar nos terços médio e inferior (Figura 2e, f), revelando tendência semelhante à pol da cana (Figura $2 b, c)$. Na porção inferior, os tratamentos induziram aumento da pureza com o transcorrer das épocas de amostragem, sendo ajustados a modelos quadráticos e, considerandose as equações, foram estimados os máximos valores aos 19, 18 e 16 DAA para os tratamentos com $\mathrm{KNO}_{3}$ (PUR 

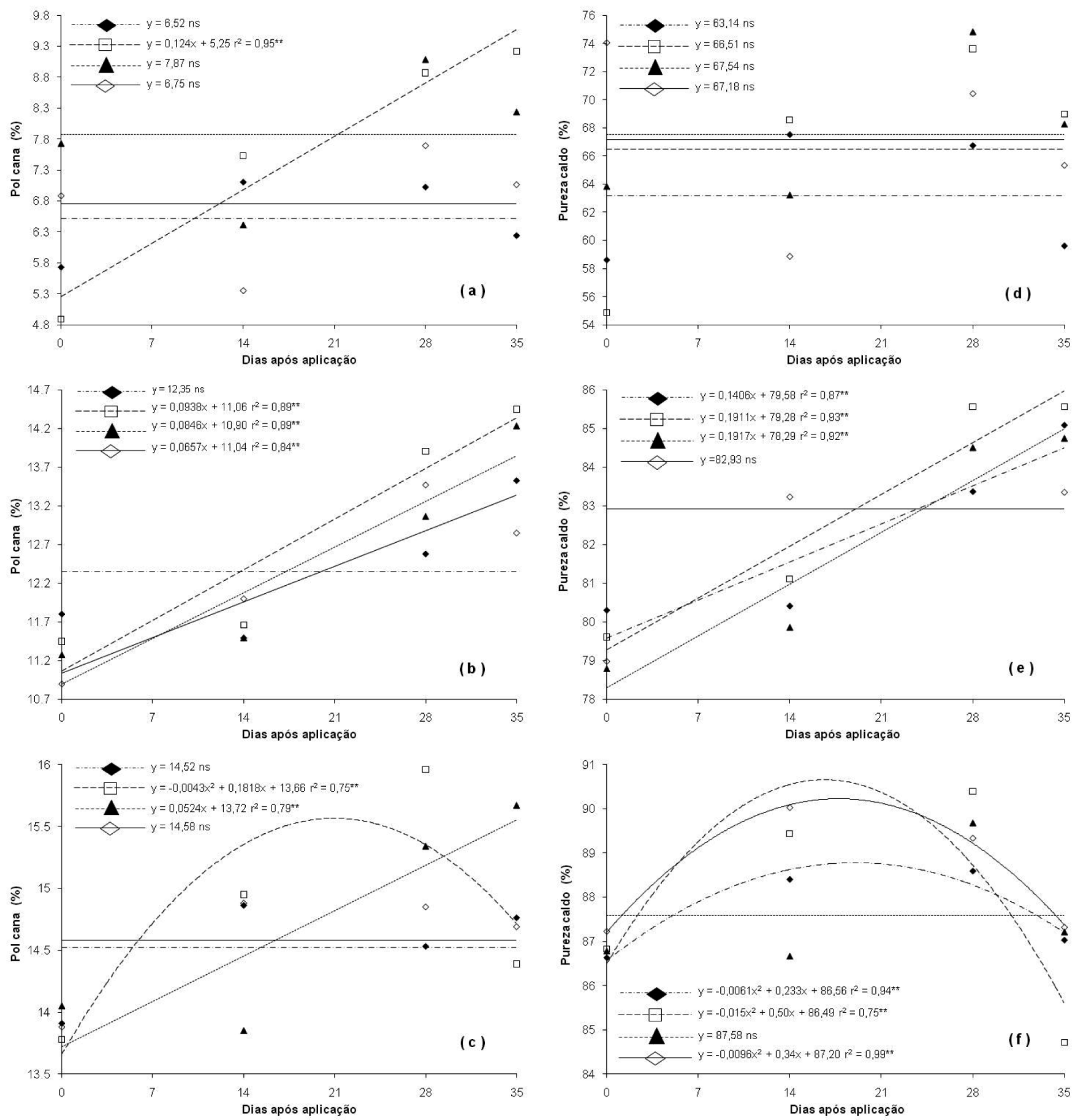

Figura 2. Pol cana (\%) e Pureza caldo $(\%)$ do terço superior (a, d), médio (b, e) e inferior (c, f) dos colmos da cana-de-açúcar RB855453, em função da aplicação dos tratamentos-testemunha ( $>$ ), sulfometuron metil (. - - $>$ - ..) glifosato $(--\dashv--)$ e $\mathrm{KNO}_{3}(-\cdot-\cdot-\cdot \cdot)$, safra 2006, em Igaraçu do Tietê (SP). ns: Não significativo. * $\mathrm{e}^{* *}$ : Significativo pelo teste t, a 5 e $1 \%$ de probabilidade respectivamente. Cada símbolo representa o valor médio de seis repetições. 
$=88,80 \%)$, testemunha (PUR $=90,20 \%$ ) e glifosato (PUR $=90,65 \%)$ respectivamente (Figura 2f). Os tratamentos elevaram a pureza no terço médio dos colmos, com resposta expressa por modelo linear crescente, com exceção do tratamento com $\mathrm{KNO}_{3}$ (Figura 2e).

Os açúcares redutores na cana tiveram influência significativa dos tratamentos nos terços médio e inferior (Figura 3b, c). Na porção inferior, a maturação natural (testemunha) e o tratamento com glifosato foram ajustados a modelos quadráticos e, considerando-se as equações, foi estimado o mínimo teor de açúcares redutores aos 18 e 17 DAA, cujos valores calculados foram de $0,46 \%$ e $0,47 \%$ respectivamente (Figura 3c). Os tratamentos proporcionaram queda nos valores de açúcares redutores no terço médio dos colmos, com resposta expressa por modelo linear decrescente, com exceção da maturação natural (testemunha) (Figura $3 b)$. Esses resultados estão de acordo com os obtidos por CAPUto et al. (2008) e FernANDES et al. (2002), que obtiveram redução expressiva no teor de açúcares redutores nos colmos com aumentos significativos na pol em diferentes variedades de cana-de-açúcar tratadas com sulfometuron metil.

Os tratamentos afetaram de forma significativa a fibra na cana na porção superior e inferior do colmo (Figura 3a, c). Para a testemunha (maturação natural), foi constatado redução no teor de fibra no terço inferior do colmo com ajuste linear, enquanto o tratamento com sulfometuron metil foi ajustado ao modelo quadrático, com quantidade mínima aos 18 DAA ( $F=10,00 \%)$ (Figura 3A). Na porção superior, para os tratamentos com $\mathrm{KNO}_{3}$ e sulfometuron metil houve resposta expressa por modelo quadrático, sendo observado menor teor de fibra na cana os 13 DAA $(F=10,30 \%)$ e aos $12 \mathrm{DAA}(\mathrm{F}=10,30 \%)$, respectivamente (Figura 3a). Os resultados corroboram com FERNANDES et al. (2002), que observaram aumento significativo de 1,28\% de fibra nos ponteiros em relação ao controle (maturação natural), em diferentes variedades de cana-de-açúcar tratadas com sulfometuron metil. Entretanto, CAPUTO et al. (2008) observaram interação entre genótipos e épocas de amostragens para a resposta ao sulfometuron metil, em que dos sete genótipos avaliados, em três houve aumento do teor de fibra dos 63 aos 126 dias após a aplicação, e em um diminuição. Segundo BARBOSA et al. (2007), há uma associação negativa entre o teor de fibra e açúcar, principalmente em variedades precoces, que possuem maior teor de sacarose e, em geral, com teor de fibra menor, de modo que a quantidade adequada de fibra é variável entre $12 \%$ e 13\%, a qual não compromete a quantidade disponível de bagaço para queima no início da safra.

Acondiçãoclimáticafavorávelaodesenvolvimento vegetativo da cultura (Figura 1) e ao crescimento em altura das plantas (Tabela 1), provavelmente pela formação de novos entrenós e/ou alongamento dos entrenós imaturos, podem explicar o incremento da fibra na porção superior da cana-de-açúcar com o transcorrer das épocas de amostragem para os tratamentos com $\mathrm{KNO}_{3}$ e sulfometuron metil (Figura 3d), comprometendo o acúmulo de sacarose nos colmos (Figura 2a). Segundo EsCHRICH (1980), o metabolismo de partição e acúmulo de sacarose é vital em todas as fases do ciclo de vida vegetal e sua utilização como fonte de energia permite disponibilizar carbono e energia necessários para as células para o processo de respiração e síntese de numerosos compostos diferenciados, dentre estes, os feixes fibrovasculares.

O tratamento com glifosato induziu aumento expressivo de $0,80 \%$ no teor de pol na porção inferior do colmo, em relação ao sulfometuron metil (PCC $=15,60 \%$ e $14,80 \%$ respectivamente) e de $1,10 \%$ em relação ao $\mathrm{KNO}_{3}$ e testemunha (PCC $=16,60 \%$ e 15,50\% respectivamente), aos 21 DAA (Figura 2c). Nesta data houve ganho de $0,4 \%$ de pol no terço médio do colmo com glifosato em comparação ao sulfometuron metil (PCC $=13,10 \%$ e 12,70\%, respectivamente) e de $0,70 \%$ em relação ao $\mathrm{KNO}_{3}$ e testemunha $(\mathrm{PCC}=$ $13,10 \%$ e $12,40 \%$, respectivamente) (Figura $2 b$ ). No terço superior do colmo, o tratamento com glifosato propiciou incremento significativo de 1 ponto de pol em comparação ao sulfometuron metil (PCC $=8,90 \%$ e $7,90 \%$ respectivamente) e de $2,40 \%$ e $2,10 \%$ em relação ao $\mathrm{KNO}_{3}$ (PCC $=8,90 \%$ e 6,50\% respectivamente) e testemunha ( $\mathrm{PCC}=8,90 \%$ e $6,80 \%$ respectivamente) aos 25 DAA respectivamente (Figura 2a).

Os tratamentos não afetaram o número de colmos por metro linear na colheita (Tabela 1). No entanto, com o tratamento com glifosato foi obtida a menor produtividade de colmos (TCH), diferindo dos tratamentos-testemunha, $\mathrm{KNO}_{3}$ e sulfometuron metil (Tabela 1). Por outro lado, não foi observada diferença significativa entre os tratamentos em relação à produtividade de açúcar (TAH) (Tabela 1). Alguns estudos relatam redução significativa na $\mathrm{TCH}$ com a utilização de glifosato em lavouras canavieiras, mas, em contrapartida, com incrementos significativos na TAH (ROMERO et al., 1998; CASTRO et al., 2002). Esse aumento se deve à produtividade de açúcar ser resultado do produto entre a produtividade de colmos e a concentração de sacarose, assim mesmo com a redução na $\mathrm{TCH}$, o maturador glifosato promoveu aumento significativo na pol (Figura 2). Em relação ao sulfometuron metil, há relatos de que o seu emprego não ocasionou efeitos prejudiciais na $\mathrm{TCH}$ em diferentes variedades de canade-açúcar (CAstro et al., 2003; CAPUTO et al., 2007).

Provavelmente, a menor produção de $\mathrm{TCH}$ com o tratamento com glifosato (Tabela 1) foi devido à 

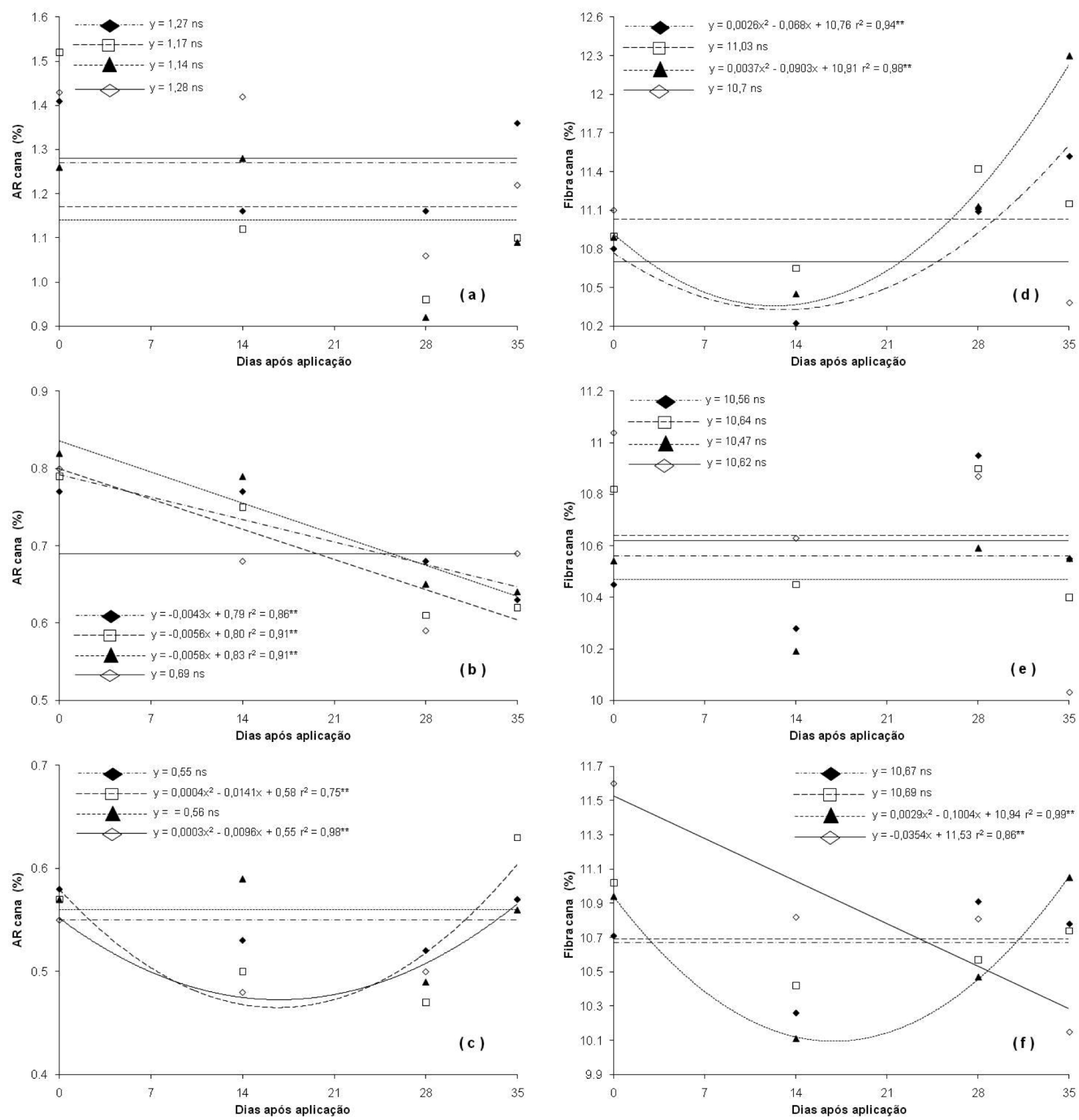

Figura 3. Açúcares redutores cana (AR, \%) e Fibra cana (\%) do terço superior (a, d), médio (b, e) e inferior (c, f) dos colmos da canade-açúcar RB855453, em função da aplicação dos tratamentos-testemunha $(\longrightarrow \diamond)$ ), sulfometuron metil (--.-glifosato (-- -- ) e $\mathrm{KNO}_{3}(-\cdot-\cdot-\cdot)$, safra 2006, em Igaraçu do Tietê (SP). ns: Não significativo. * e **: Significativo pelo teste t, a 5 e $1 \%$ de probabilidade respectivamente. Cada símbolo representa o valor médio de seis repetições. 
Tabela 1. Comprimento, diâmetro e número de colmos, produtividade de colmos (TCH), produtividade de açúcar (TAH) e margem de contribuição agrícola (MCA) da cana-de-açúcar variedade RB855453 sob efeito de maturadores. Igaraçu do Tietê (SP), 2006

\begin{tabular}{|c|c|c|c|c|}
\hline \multirow{2}{*}{ Tratamentos } & \multicolumn{2}{|c|}{ Comprimento $(\mathrm{m})^{(1)}$} & \multicolumn{2}{|c|}{ Diâmetro (mm) ${ }^{(1)}$} \\
\hline & 0 DAA & 35 DAA & 0 DAA & 35 DAA \\
\hline $\mathrm{KNO}_{3}$ & $2,22 \mathrm{bB}$ & $2,45 \mathrm{aA}$ & $32,71 \mathrm{aA}$ & 34,88 aA \\
\hline Glifosato & $2,35 \mathrm{aA}$ & $2,38 \mathrm{aA}$ & $33,74 \mathrm{aA}$ & 35,39 aA \\
\hline Sulfometuron metil & $2,19 \mathrm{bB}$ & $2,44 \mathrm{aA}$ & $33,28 \mathrm{aA}$ & $33,57 \mathrm{aA}$ \\
\hline Testemunha & $2,28 \mathrm{abB}$ & $2,46 \mathrm{aA}$ & $31,75 \mathrm{aA}$ & $33,01 \mathrm{aA}$ \\
\hline C.V. $(\%)$ & & & & \\
\hline \multirow{2}{*}{ Tratamentos } & \multicolumn{4}{|c|}{ Número de colmos por metro ${ }^{(1)}$} \\
\hline & \multicolumn{4}{|c|}{35 DAA } \\
\hline $\mathrm{KNO}_{3}$ & \multicolumn{4}{|c|}{$11,00 \mathrm{a}$} \\
\hline Glifosato & \multicolumn{4}{|c|}{$11,00 \mathrm{a}$} \\
\hline Sulfometuron metil & \multicolumn{4}{|c|}{$11,00 \mathrm{a}$} \\
\hline Testemunha & \multicolumn{4}{|c|}{$11,00 \mathrm{a}$} \\
\hline C.V. $(\%)$ & \multicolumn{4}{|c|}{6,32} \\
\hline \multirow{2}{*}{ Tratamentos } & TCH $\left(\mathrm{t} \mathrm{ha}^{-1}\right)$ & TAH & & $\left.\mathrm{S} \$ \mathrm{ha}^{-1}\right)^{(1)}$ \\
\hline & \multicolumn{4}{|c|}{35 DAA } \\
\hline $\mathrm{KNO}_{3}$ & $133,00 \mathrm{a}$ & & & $90 \mathrm{~b}$ \\
\hline Glifosato & $123,00 \mathrm{~b}$ & & &, $50 \mathrm{a}$ \\
\hline Sulfometuron metil & $134,00 \mathrm{a}$ & & &, $50 \mathrm{a}$ \\
\hline Testemunha & $139,00 \mathrm{a}$ & & & $40 \mathrm{~b}$ \\
\hline C.V. $(\%)$ & 5,75 & & & 46 \\
\hline
\end{tabular}

Médias seguidas de letras distintas, minúscula na coluna e maiúscula na linha, diferem estatisticamente pelo teste LSD ( $\mathrm{P}=0,05)$.

(1) Aplicação dos tratamentos em 14/3/2006 e colheita aos 35 dias após aplicação (DAA).

dessecação da cana-de-açúcar, consequência da perda de umidade do material vegetal e/ou do retardamento do processo de desenvolvimento vegetativo, medido por meio do comprimento dos colmos. Todavia, o tratamento contribuiu de forma marcante para a melhoria na qualidade tecnológica da matéria-prima, principalmente na porção superior do colmo (Figuras $2 \mathrm{e}$ 3). Assim, é possível inferir que a melhoria na qualidade tecnológica da matéria-prima, principalmente na porção superior do colmo, como constatado no tratamento com glifosato (Figuras 2 e 3), possibilita maior altura de desponte, compensando as perdas na $\mathrm{TCH}$, com reflexo positivo na TAH e na MCA (Tabela 1). Tal afirmação tem fundamento em estudo realizado por STUPIELLO (2000), quando relata que a ponta ou ponteiro corresponde aos entrenós imaturos enquanto o cartucho contém o meristema apical e parte das folhas e, em condições normais, representam de $10 \%$ a $15 \%$ em relação à cana total. Também Oliveira e Bullio (1989) afirmaram que a colheita da cana com ponta promoveu acréscimos no rendimento do corte manual da ordem de $40 \%$ para cana-planta e de até $80 \%$ para a cana-soca, podendo conferir aumento na produtividade de colmos.

Quantoàmargemdecontribuiçãoagrícola,constatouse que os tratamentos com glifosato e sulfometurom metil propiciaram retorno econômico significativamente maior, diferindo do tratamento com $\mathrm{KNO}_{3}$ e do controle (Tabela 1), decorrente da melhoria na qualidade tecnológica da matéria-prima (Figuras 2 e 3 ) e da TAH (Tabela 1). O retorno econômico com o uso de maturadores depende, dentre outros fatores, da produtividade, e em áreas de alta produtividade, pequenos aumentos na qualidade resultam em vantagem econômica (FerNANDES, 2003). Conforme FERNANDES et al. (2002), os efeitos positivos na qualidade tecnológica dos ponteiros e colmos, nas áreas tratadas com sulfometuron metil, produziram aumentos significativos da margem de contribuição.

\section{CONCLUSÕES}

1. Os tratamentos com $\mathrm{KNO}_{3}$ e sulfometuron metil, assim como a testemunha, não promovem prejuízos ao comprimento dos colmos.

2. Os tratamentos com glifosato e sulfometuron metil propiciam melhoria na qualidade tecnológica da matéria-prima, determinada até os 35 dias após aplicação, contribuindo para o processo de maturação e possibilitando antecipar o corte em relação à maturação natural (testemunha) e ao tratamento com $\mathrm{KNO}_{3^{\prime}}$ com maior retorno econômico. 
3. O tratamento com glifosato reduz a produtividade de colmos, mas eleva a pol da cana na porção superior dos colmos, possibilitando maior altura de desponte.

\section{AGRADECIMENTOS}

À Fundação de Amparo à Pesquisa do Estado de São Paulo (Fapesp) pelo apoio financeiro ao projeto de pesquisa; ao CNPq pela concessão de bolsa de produtividade em pesquisa a Carlos Alexandre Costa Crusciol e Marcelo de Almeida Silva; ao Grupo COSAN - Unidade Barra (Usina da Barra), pela permissão de realização do experimento em sua área experimental.

\section{REFERÊNCIAS}

BARBOSA, M.H.P.; SILVEIRA, L.C.I.; MACÊDO, G.A.R.; PAES, J.M.V. Variedades melhoradas de cana-de-açúcar para Minas Gerais. Informe Agropecuário, v.28, p.20-24, 2007.

BARRETO, L. Efecto de varias porcentajes y tipos de "trash" em rendimiento de azucar. International Sugar Journal, v.93, p.191-194, 1991.

BELODI, C.O. Processamento de cana sem desponte Experiência da Açúcareira Quatá. STAB, Açúcar, Álcool e Subprodutos, v.6, p.41-48, 1988.

CAPUTO, M.M.; BEAUCLAIR, E.G.F.; SILVA, M.A.; PIEDADE, S.M.S. Resposta de genótipos de cana-de-açúcar à aplicação de indutores de maturação. Bragantia, v.67, p.15-23, 2008.

CAPUTO, M.M.; SILVA, M.A.; BEAUCLAIR, E.G.F.; GAVA, G.J.C. Acúmulo de sacarose, produtividade e florescimento de cana-de-açúcar sob reguladores vegetais. Interciencia, v.32, p.834-840, 2007.

CASTRO, P.R.C. Maturadores químicos em cana-de-açúcar. Saccharum, v.1, p.12-16, 1999.

CASTRO, P.R.C.; CÂMARA, G.M.S.; CÉSAR, M.A.A.; NOGUEIRA, M.C.S. Ação comparada de maturadores em cultivares de cana-de-açúcar. Álcool e Açúcar, v.73, p.36-39, 1994.

CASTRO, P.R.C.; DONADONI, P.C.I.; PAGGIARO, C.M.; WATANABE, S.; TAVARES, S.; PANINI, E.L. Afinidade do sulfometuron metil com adjuvantes. STAB, Açúcar, Álcool e Subprodutos, v.22, p.42-43, 2003.

CASTRO, P.R.C.; KLUGE, A. Ecofisiologia de culturas extrativas: cana-de-açúcar, seringueira; coqueiro; dendezeiro e oliveira. Cosmópolis: Stoller do Brasil, 2001. 138p.

CASTRO, P.R.C.; ZAMBON, S.; SANSÍGOLO, M.A.; BELTRAME, J.A.; NOGUEIRA, M.C.S. Ação comparada de
Ethrel, Fuzilade e Roundup, em duas épocas de aplicação, na maturação e produtividade da cana-de-açúcar SP70-1143. Revista de Agricultura, v.77, p.23-38, 2002.

COPERSUCAR. Centro de Tecnologia de Cana (CTC). Manual de controle químico da fabricação de açúcar. Piracicaba, 1999. p.1-36.

DEUBER, R. Maturação da cana-de-açúcar na Região Sudeste do Brasil. In: SEMINÁRIO DE TECNOLOGIA AGRONÔMICA, 4., Piracicaba. Anais... Piracicaba: Copersucar, 1988. p.33-40.

ESCHRICH, W. Free space invertase, its possible role in phloem unloading. Berichte der Deutschen Botanischen Gesellschaft, n.93, p.363-378, 1980.

FERNANDES, A.C. Cálculos na agroindústria da cana-deaçúcar. Piracicaba: STAB, 2003. 240p.

FERNANDES, A.C.; STUPIELLO, J.P.; UCHOA, P.E.A. Utilização do Curavial para melhoria da qualidade da canade-açúcar. STAB, Açúcar, Álcool e Subprodutos, v.20, p.43-46, 2002.

LEITE, G.H.P. Maturação induzida, alterações fisiológicas, produtividade e qualidade tecnológica da cana-deaçúcar. 2005. 156p. Dissertação (Mestrado em Agronomia Agricultura), Universidade Estadual Paulista, Botucatu.

OLIVEIRA, D.T.; BULLIO, M.T. Aspectos técnico-econômicos do corte e moagem da cana com ponta. Piracicaba: Copersucar, 1989. p.18-23. (Boletim Técnico, 46)

OVEJERO, R.F.L.; CHRISTOFFOLETI, P.J.; VARGAS, L. Resistência de plantas daninhas a herbicidas. In: Manual de manejo e controle de plantas daninhas. Bento Gonçalves: Embrapa Uva e Vinho, 2004. p.185-215.

RODRIGUES, T.J.D.; LEITE, I.C. Fisiologia vegetal: hormônios das plantas. Jaboticabal: Funep, 2004. 78p.

ROMERO, E.R.; SCANDALIARIS, J.; OLEA, I.; DIAZ, H; SOTILLO, S.; DURÁN, A. La maduración en caña de azúcar. II. Elglifosato como madurador químico. Avance Agroindustrial, v.17, p.14-18, 1996.

ROMERO, E.R.; SCANDALIARIS, J.; RUFINO, M; DURÁN, A.; DIAZ, F. Respuesta de la caña de azúcar a la aplicación de glifosato como madurador. I. Efectos en la calidad fabril e influencia de los factores ambientales. Avance Agroindustrial, v.19, p.7-10, 1998.

ROMERO, E.R.; SCANDALIARIS, J.; RUFINO, M.; DURÁN, A.; SOTOMAYOR, L.; QUIROGA, V.; MORALES, M. Actualización de las recomendaciones de manejo de glifosato como madurador de la caña de azúcar. Avance Agroindustrial, v.21, p.22-27, 2000. 
ROMERO, E.R.; SOTOMAYOR, L.; TONATTO, J.; ALONSO, L.; SCANDALIARIS, J.; NEME, M.F.L. Maduración química de los cañaverales: criteios y recomendaciones para implementar un programa de manejo. Avance Agroindustrial, v.24, p.10-14, 2003.

RUAS, D.G.G.; PARAZZI, F.; MARGARIDO, L.A.C.; BERGNER, H.C.; TOLEDO, J.C. Colheita sem desponte da cana-de-açúcar - uma experiência. In: CONGRESSO
NACIONAL DA STAB, 4., Olinda, 1987. Anais... Piracicaba: STAB, 1987. p.177-181.

STUPIELLO, J.P. Pontas de cana: problema industrial? STAB, Açúcar, Álcool e Subprodutos, v.18, p.12, 2000.

ZARPELON, F. Processamento industrial de cana não despontada: experiência da Usina Ester. STAB, Açúcar, Álcool e Subprodutos,v.6, p.37-42, 1988. 